\title{
solo \\ Zooarqueología y tafonomía del Período Tardío- Inca en Peñas Coloradas, Antofagasta de la Sierra (Puna de Catamarca, Argentina)
} RMA

Dossier

\author{
Jorge Guillermo Ortiz* y Silvana Valeria Urquiza**
}

* Instituto de Arqueología y Museo, Facultad de Ciencias Naturales e IML, Universidad Nacional de Tucumán, Argentina. E-mail: jgortiz21@yahoo.com.ar;

** Instituto de Arqueología y Museo, Facultad de Ciencias Naturales e IML, Universidad Nacional de Tucumán y CONICET. Instituto Superior de Estudios Sociales.E-mail: silvanaurquiza@yahoo.com

\begin{abstract}
Resumen
Se presenta el análisis integrado del conjunto arqueofaunístico, constituido por vertebrados e invertebrados, del sitio Peñas Coloradas 3-cumbre (PC3-C), Antofagasta de la Sierra (Catamarca, Argentina). El sitio se localiza en la cumbre de un farallón de ignimbrita y está conformado por estructuras arquitectónicas asignadas a momentos Tardíos-Incas, algunas de las cuales han sido reutilizadas hasta principios del siglo XX. Con la finalidad de complementar los datos y reconstruir la historia tafonómica de los conjuntos faunísticos, se estudió el contexto sedimentario mediante métodos físico-químicos (textura; $\mathrm{pH}$; determinación de albúmina, P y MO). Los materiales analizados brindaron datos sobre algunas de las actividades realizadas en las estructuras, el consumo de animales, temporalidad, estacionalidad de las ocupaciones, y sobre los procesos diagenéticos actuantes. La integración contextual de los datos materiales analizados y del emplazamiento del sitio y sus estructuras, nos permite inferir prácticas sociales diferenciadas entre las estructuras con cubierta y sin cubierta. Las primeras, se vinculan a depósitos de alimentos y manufacturas, mientras que las segundas se asocian con prácticas residenciales, procesamiento y consumo de alimentos.
\end{abstract}

Palabras claves: Zooarqueología;Tafonomía; Entomología; Puna argentina; Tardío e Inca.

Zooarchaeology and taphonomy of Peñas Coloradas (Antofagasta de la Sierra, Puna de Catamarca, Argentina) Late and Inca Period

\begin{abstract}
In this paper, an integrated analysis of archaeofaunal data consisting of vertebrates and invertebrates of the Peñas Coloradas 3-summit (PC3-C), Antofagasta de la Sierra (Catamarca, Argentina) is conducted. The site is located at the top of an ignimbrite hill and is composed of architectural structures attributed to Late Inca times, some of which had been re-used until the early 20th century. In order to complement the data and reconstruct the taphonomic history of the faunal assemblages, we studied the sedimentary context by physicochemical methods (texture, $\mathrm{pH}$, determination of albumin, $P$ and $M O$ ). The material tested has provided data on some of the activities in the structures, animal consumption, timing and seasonality of occupations and diagenetic processes. Data integration as well as site and structure location allows inferring social practices that indicate different functions served between structures with and without roof. The former are linked to food and manufacture storage, while the latter are associated to residential practices, processing and consumption.
\end{abstract}

Keywords: Zooarchaeology; Taphonomy; Entomology; Argentine Puna; Late and Inca periods.

En este trabajo se aborda desde una perspectiva zooarqueológica y tafonómica la problemática del periodo Tardío-Inca del sitio Peñas Coloradas 3 cumbre (PC3-c)

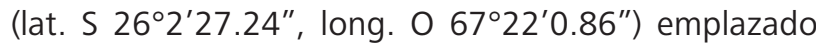
$5 \mathrm{Km}$ hacia el Noreste de la desembocadura del río Las Pitas en Antofagasta de la Sierra, provincia de Catamarca (Argentina).

El área de estudio se sitúa en la Puna Desértica o Salada, caracterizada entre otros aspectos, por sus condiciones climáticas de marcada aridez y amplitud térmica (Cabrera 1976; Santoro y Núñez 1987; Troll 1958). La Cuenca de Antofagasta de la Sierra pertenece al sistema endorreico de los ríos Toconquis-Calalaste-Punilla/Antofagasta. Todos desaguan en la laguna de Antofagasta, circunscrita por dos volcanes y un campo de lavas. Este sistema de ríos recibe afluentes en ambas márgenes. Uno de estos afluentes es el río Las Pitas en cuyas márgenes se localizan diversos sitios arqueológicos, entre los que se encuentra Peñas Coloradas. Dentro de la microrregión de Antofagasta

Recibido 23-04-2012. Recibido con correcciones 26-07-2012. Aceptado 14-10-2012 


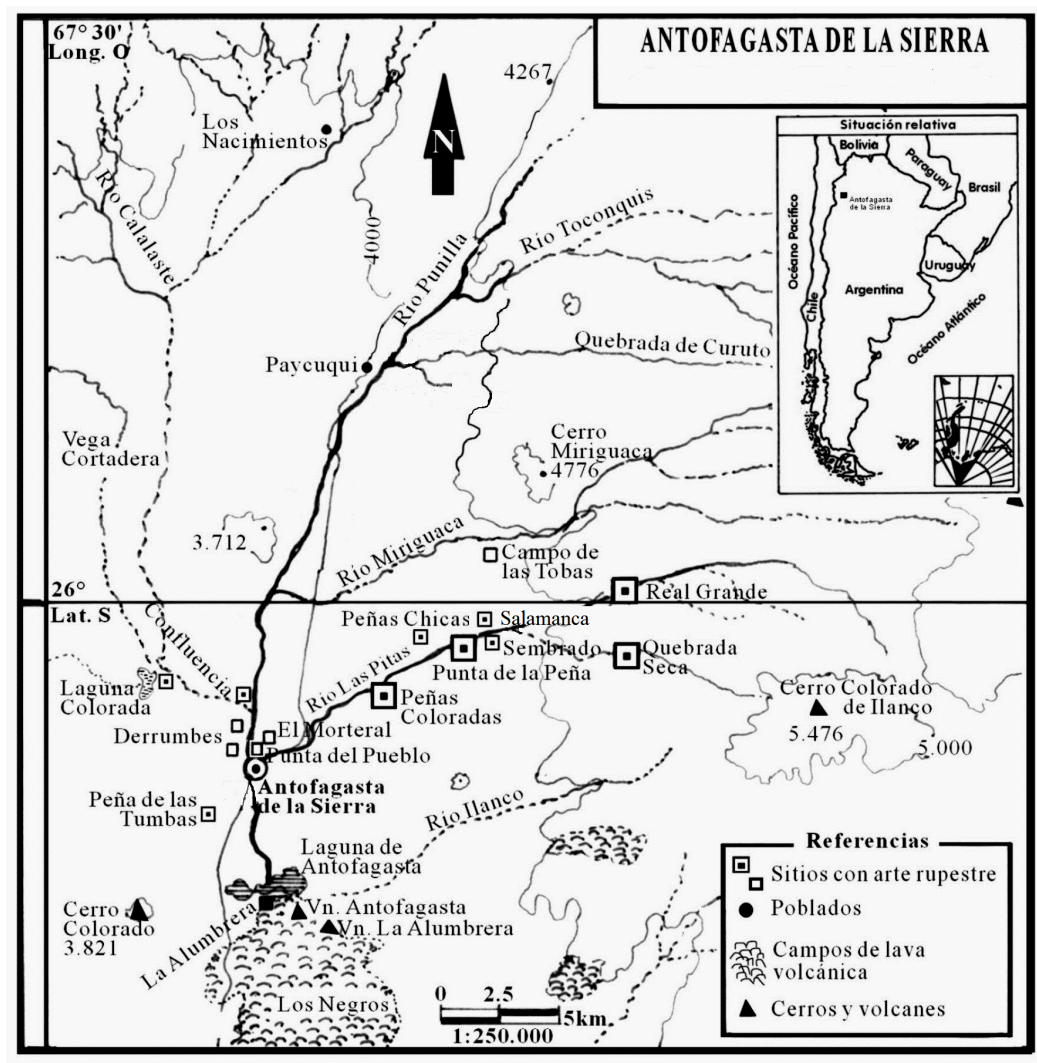

Figura 1. Mapa de ubicación del sitio Peñas Coloradas en Antofagasta de la Sierra, provincia de Catamarca (Modificado de Aschero 2000).

Figure 1. Map showing the location of Peñas Coloradas site in Antofagasta de la Sierra, Catamarca province (Modified from Aschero 2000).

de la Sierra, el sitio se encuentra entre los 3550 a 3900 m.s.n.m en el denominado Sector Intermedio (Olivera 1992) por la disponibilidad de los recursos, y de acuerdo a su topografía y recursos vegetales en la Zona B o Vega Intermedia (Aschero 2006). Esta ubicación intermedia actualmente es una vía de tránsito entre el Fondo de Cuenca (3400 a 3550 msnm) y las vegas en las Quebradas de Altura como Quebrada Seca y Real Grande (3800 a 4600 msnm) (Cohen 2011; Podestá 1990).

La localidad arqueológica de Peñas Coloradas (PC) comprende cuatro farallones de ignimbrita, correspondiendo a los sitios arqueológicos PC1, PC2, PC3, PC4. En la cima del tercero, a 3549 msnm, se localiza el sitio Peñas Coloradas 3-cumbre (PC3-c) (Cohen 2009 a). PC comprende los períodos Temprano o Formativo, Medio, Desarrollos Regionales o Tardío e Inka. Ha sido reconocido principalmente por sus paneles con cuantiosas representaciones rupestres, donde predomina la figura del camélido, aislado, en hatos, o alineados en vinculación o no a antropomorfos, los cuales han sido relacionados a grupos agropastoriles (Aschero 1999; Cohen 2009a, 2010; Olivera 1989; Olivera y Podestá 1991; Podestá 1990; Weiser 1923 en Cohen 2009b). Cohen (2011) ha incorporado el análisis de la arquitectura del TardíoInca destacando el emplazamiento del sitio PC3-c, localizado en la cumbre del farallón. El sitio presenta restos de una muralla pircada al Este y Sur, y 26 estructuras dispuestas en dos grandes grupos, uno de los cuales se sitúa en el sector central de la cumbre (Cohen 2010) y contiene las estructuras arquitectónicas que se analizan en este trabajo. Cohen (2010) realizó una tipología de las estructuras y obtuvo dataciones del material recuperado, con algunas calibraciones en un rango de $2 \sigma$, para la capa 2 de las mismas:

a- Estructuras en falsa bóveda (II-XIII): presentan aproximadamente $3 \mathrm{~m}^{2}$ de diámetro. El fechado para la estructura II es AMS 332 444 años AP (AA89397)/ 1450-1650 cal DC, y para la XIII, AMS 194+38 años AP (AA89398).

b- Estructuras en cista o pozo (V-XI): de $2 \mathrm{~m}^{2}$ de diámetro. La estructura $\mathrm{V}$ presenta una datación de AMS 128 \pm 32 años AP (AA89401) y la XI, AMS 162 \pm 32 años AP (AA89400).

c- Estructuras de pircado de dimensiones mayores (III, VIII, XV): con un diámetro de $5 \mathrm{~m}^{2}$ aproximadamente. El fechado de la estructura III es AMS $1095 \pm 48$ años AP (AA89396)/ 810-1030 cal DC, y el de la estructura VIII C14 $850 \pm 60$ años AP (LP- 1930)/ 1030-1280 cal DC. En la estructura XV no se encontraron vestigios materiales.

d- Estructura "Hondonada" $(X)$ : posee un diámetro de alrededor de $8 \mathrm{~m}^{2}$ y su datación es AMS $808 \pm 42$ años AP (AA89399)/ 1150-1290 cal DC 2б.

e- Estructura "En Corte" (EC): $1 \mathrm{~m}^{2}$ de diámetro y sin vestigios materiales.

Las estructuras en falsa bóveda, cista o pozo y en corte, se vincularían a contextos funerarios y/o depósitos; mientras que las estructuras de pircado y hondonada, estarían relacionadas con prácticas residenciales, procesamiento y consumo de alimentos, y habitación (Cohen 2010).

En cuanto a la estratigrafía del sitio PC3-c, se registraron 4 capas (Cohen 2010). La capa 1, se compone de arena gruesa y clastos de ignimbrita de hasta $15 \mathrm{~cm}$, con baja densidad de vestigios materiales, ausencia de restos óseos faunísticos, y alta concentración de excrementos de ovicápridos actuales. La capa 2, de 13 a $20 \mathrm{~cm}$ de espesor, está conformada por arena fina rojiza con alta densidad de vestigios materiales culturales. La capa 3 , de $0,5 \mathrm{~cm}$ de espesor, presenta sedimento fino rojizo, mientras que la 4 corresponde a la roca madre (ignimbrita). Solo la capa 2 presenta restos zooarqueológicos y está asociada a los 
pisos de ocupación de las estructuras, por lo que es la que se analiza en este trabajo.

El estudio conjunto del registro óseo, sedimentario y entomológico, permite entender los contextos ambientales particulares que se fueron dando dentro de un sitio arqueológico. Con el propósito de aportar al conocimiento del manejo animal por parte de los pobladores del período Tardío-Inca en el área del río Las Pitas, e identificar los diferentes agentes tafonómicos que influyeron en la formación del registro arqueológico de las estructuras de PC3-c, se realizó un análisis conjunto del registro faunístico integrando las características cualitativas y cuantitativas de los sedimentos que los contuvieron.

Para esta área de la Puna, son variados los enfoques aplicados en las investigaciones zooarqueológicas (Elkin 1996; Grant 2008; Olivera 1997; Olivera y Elkin 1994; Olivera y Grant 2008; Reigadas 1992, 1994, 1995, 2008; Urquiza 2004, 2009a y b; Urquiza y Aschero 2006; Urquiza et al. 2008 y 2009b; entre otros) y tafonómicas (Nasti 1991 y 1995; Mondini 2002, 2003, 2004 y 2007; Urquiza et al. 2009a; Urquiza 2009a, 2010; entre otros). El enfoque original de este trabajo radica en la aplicación de estudios geo-bioquímicos y entomoarqueológicos, disciplinas aún incipientes en la arqueología argentina, pero con antecedentes para el estudio (Urquiza 2009a, 2010; Urquiza et al. 2009).

\section{Metodología}

El análisis en laboratorio se dividió en dos etapas teniendo en cuenta el tipo de material; arqueofaunístico y muestras sedimentarias. Estos materiales provienen de las estructuras mencionadas previamente y de un testigo de referencia seleccionado de la zona oeste del sitio, sin alteración antrópica.

La muestra arqueofaunística se compone de vertebrados e invertebrados. El material entomológico, exoesqueletos y pupas, fue comparado con la colección del Instituto Abraham Willink (Fundación Miguel Lillo-Tucumán) para su identificación taxonómica y anatómica. El análisis del conjunto óseo se llevó a cabo mediante identificaciones anatómicas y taxonómicas, análisis tafonómicos (Mengoni Goñalons 1988, 1999; Huelsbeck 1991; Lyman 1994; Reitz and Wing 1999; entre otros) y análisis de las variables morfométricas postcraneales (Von den Driesch 1976; Elkin 1996; Izeta 2007). Se utilizó el concepto de clases de tamaño corporal (Brain 1981) para agrupar especies o géneros, con una escala modificada para el noroeste argentino (Izeta 2004, 2007). La edad se determinó según el estado de fusión epifisiaria de los huesos largos (Kent 1982; Kaufmann 2009). En la cuantificación del conjunto óseo se tuvo en cuenta el número de restos (NR), identificados o no; la abundancia de las especies animales se evaluó a través del número de

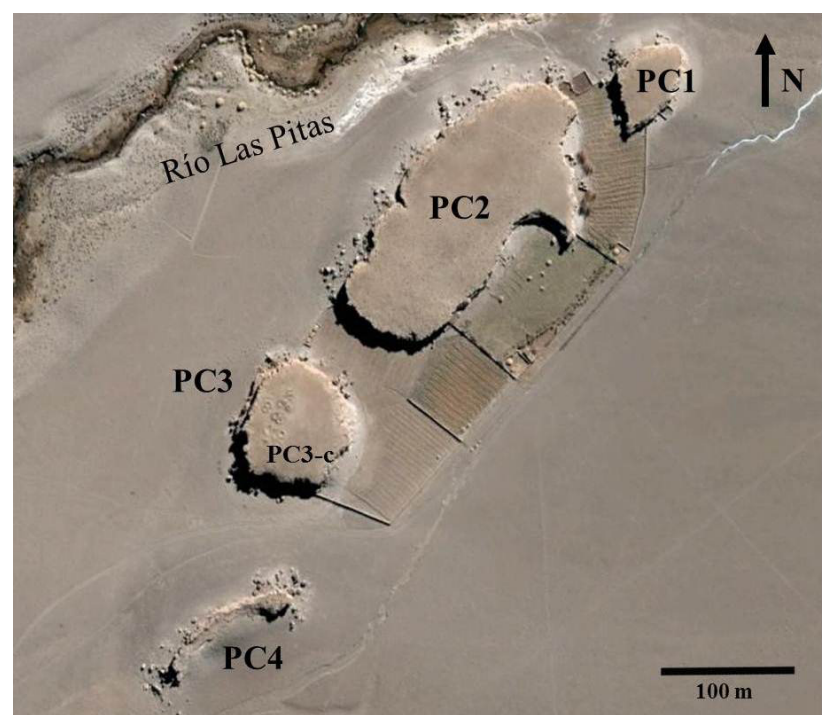

Figura 2. Imagen satelital del sitio Peñas Coloradas (PC1, PC2, PC3 y P(4). Escala: 100m.

Figure 2. Satellite image of Peñas Coloradas site $(P C 1, P C 2, P C 3$ and P(4). Scale bar $100 m$.

especimenes identificados por taxón (NISP) y el número mínimo de individuos (MNI). Posteriormente se realizaron observaciones macroscópicas con el fin de establecer la presencia de marcas, huellas y fracturas de origen cultural y/o no antrópicas (Binford 1981; Gifford 1981; Gutiérrez 2004; Lyman 1994; Mondini 2003), como así también los estadios de meteorización (Behrensmeyer 1978) y alteraciones térmicas (Nicholson 1993). El número de especimenes óseos que presentan marcas no antrópicas fue cuantificado mediante el Porcentaje de Marcas No Antrópicas (PNA) y el Índice de Marcas No Antrópicas (INA) (Urquiza et al. 2008, Urquiza 2009a).

Los análisis físico-químicos de sedimento se realizaron en el Laboratorio de Suelos de la Facultad de Ciencias Naturales e Instituto Miguel Lillo (Universidad Nacional de Tucumán) (Ortiz 2010). Para evaluar el contenido de materia orgánica del suelo, se determinó el porcentaje de carbono orgánico mediante el método de Walkley y Black (Walkley y Black 1938). Las estimaciones relativas de fósforo $(P)$ se realizaron mediante la técnica cualitativa de Eidt (1973) (Barba et al. 1991). El P una vez en el sedimento no sufre lixiviación y se fija de manera insoluble, pero en ambientes ácidos se torna soluble, por lo que también se determinaron las condiciones de acidez de la matriz sedimentaria. Las medidas de $\mathrm{pH}$ se realizaron mediante el empleo de un peachímetro Altromix en relación sueloagua 1:2,5. La determinación de la presencia/ausencia de albúmina en los sedimentos proviene de la aplicación de una técnica utilizada en los fragmentos de cerámica propuesta por Barba (Ibid.) y modificada por Urquiza (2009a, 2010) para ser aplicada a los sedimentos de sitios arqueológicos. Para la determinación de la textura del suelo se empleó el método indirecto del hidrómetro de Bouyoucos (Bouyoucos 1962). Para observar la 
distribución de las muestras en el triángulo de texturas se empleó el programa Texture AutoLookup (TAL) 4.2.

\section{Resultados}

\section{Muestra arqueofaunística}

El conjunto arqueofaunístico de las estructuras analizadas, cuenta con un total de 1206 restos, conformados por vertebrados e invertebrados. Además se recuperaron fragmentos de cueros, tendones, coprolitos, vellones, lanas, cordeles y textiles.

Las partes esqueletales con NR: 1032, corresponden a más de la mitad de la muestra $(85,6 \%)$ entre enteras, fragmentos y astillas óseas. Las estructuras que presentaron mayor cantidad de huesos animales fueron los recintos VIII (45\%), X (23\%), XI (13\%), III (9\%) y en menor medida se encuentran las estructuras II (5\%), V(3\%) y XIII (2\%).

En el caso del material entomológico la muestra se conforma por exoesqueletos de invertebrados enteros, fragmentados y pupas, cuyo NR suma 174 (14,4\%). En tanto que el NISP total de los vertebrados es 851, con MNI: 19; para los invertebrados el NISP y MNI computan 82 cada uno (Figura 3).

La entomofauna recuperada en las estructuras pertenece a Diptera (56\%); Coleóptera: Curculionidae (13\%) y Tenebrionidae (10\%); Odonata: Anisoptera (5\%); y fragmentos de capullos y pupas indeterminados (16\%) (Tabla 1).

El total del conjunto óseo corresponde a mamíferos, entre los cuales se identificó como artiodáctilos un porcentaje del $18 \%$, registrándose suidos (1\%) y camélidos (53\%) identificando un $6 \%$ como Lama glama (MNI: 3). Dentro de la muestra de roedores encontramos un $1 \%$ de indeterminados, así como especímenes de Cricetidae: Phyllotis sp. $(0,4 \%)$ y Chinchillidae: Lagidium viscacia (20,3\%). El resto de la muestra comprende Cingulata con un $0,3 \%$ representado por Dasypodidae (Figura 4). Dentro del total de especímenes identificados, un 52\% corresponde a la estructura VIII (Tabla 2). Con respecto al rango etario, se recuperaron huesos sin fusionar de artiodáctilos (Suidae y Camelidae) y de roedores (L. viscacia), el resto corresponde a especímenes semifusionados y fusionados. Las partes esqueletales sin fusionar de camélidos se encuentran asociados a las estructuras VIII, X y XI (Tabla 3).

Un 59\% de la muestra se encuentra entre los estadios de meteorización 2 y 3, mientras que un 18\% de las partes esqueletales se ubica en el estadio 5 de la escala de Behrensmeyer (1978) (Tabla 4). En las estructuras con cubierta el NR es menor $(23,6 \%)$ en relación a las estructuras sin cubierta (76,6\%). Para las primeras existe un mayor porcentaje en los estadios de meteorización 1 y 3; mientras que para las segundas predominan los estadios 2, 3 y 5 .

El grado de fragmentación de la muestra es alto, registrándose huesos enteros sólo en las estructuras VIII (NR: 3) y XI (NR: 18), en algunos casos las fragmentaciones se relacionan con alteraciones térmicas. El conjunto óseo termoalterado asciende a NR: 193 (19\% del total), concerniendo un 50\% a la Estructura VIII. Si bien se registran todos los grados de termoalteración (sensu Nicholson 1993), el grado 3 sobresale con un $42 \%$ sobre el total. En todas las estructuras encontramos huellas antrópicas (cortes y golpes intencionales, huesos pulidos), sin embargo, sólo en la V, VIII, XI y XIII se localizaron marcas no antrópicas, prevaleciendo las de roedor. Algunos huesos de la estructura VIII presentan en su

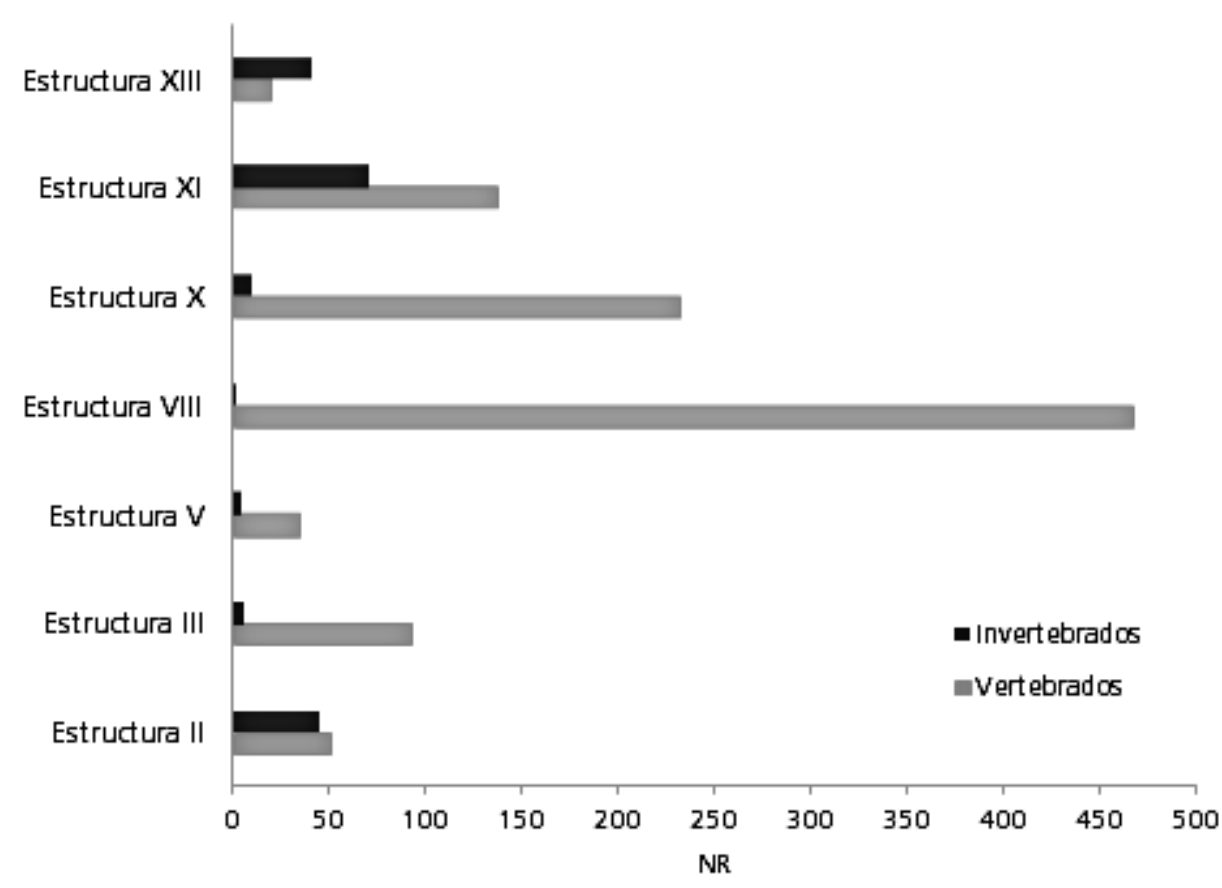

Figura 3. NR total de la muestra de vertebrados e invertebrados discriminado por estructuras arquitectónicas.

Figure 3. NR total sample of vertebrates and invertebrates discriminated against the architectural structures. 


\begin{tabular}{|c|c|c|c|c|c|c|c|c|}
\hline \multicolumn{2}{|c|}{ Estructura/ Taxón } & \multirow{2}{*}{$\begin{array}{l}\text { NR } \\
44\end{array}$} & \multirow{2}{*}{$\begin{array}{c}\begin{array}{c}\text { Coleoptera: } \\
\text { Curculionidae }\end{array} \\
2\end{array}$} & \multirow{2}{*}{$\begin{array}{c}\begin{array}{c}\text { Coleoptera: } \\
\text { Tenebrionidae }\end{array} \\
3\end{array}$} & \multirow{2}{*}{$\begin{array}{c}\begin{array}{c}\text { Odonata: } \\
\text { Anisoptera }\end{array} \\
0\end{array}$} & \multirow{2}{*}{$\begin{array}{c}\begin{array}{c}\text { Diptera: } \\
\text { Calliphoridae }\end{array} \\
5\end{array}$} & \multirow{2}{*}{$\begin{array}{c}\begin{array}{c}\text { Pupas } \\
\text { Indeterminadas }\end{array} \\
4\end{array}$} & \multirow{2}{*}{$\begin{array}{c}\begin{array}{c}\text { NISP total y } \\
\text { Porcentajes }\end{array} \\
14(17,1 \%)\end{array}$} \\
\hline \multirow{5}{*}{ con cubierta } & II & & & & & & & \\
\hline & $\mathbf{V}$ & 4 & 0 & 1 & 0 & 0 & 0 & $1(1,2 \%)$ \\
\hline & $\mathbf{X I}$ & 70 & 3 & 2 & 2 & 17 & 0 & $24(29,3 \%)$ \\
\hline & XIII & 41 & 6 & 1 & 2 & 23 & 1 & $33(40,2 \%)$ \\
\hline & Subtotal & 159 & 11 & 7 & 4 & 45 & 5 & $72(87,8 \%)$ \\
\hline \multirow{4}{*}{ sin cubierta } & III & 5 & 0 & 0 & 0 & 1 & 3 & $4(5 \%)$ \\
\hline & VIII & 1 & 0 & 1 & 0 & 0 & 0 & $1(1,2 \%)$ \\
\hline & $x$ & 9 & 0 & 0 & 0 & 0 & 5 & $5(6 \%)$ \\
\hline & Subtotal & 15 & 0 & 1 & 0 & 1 & 8 & $10(12,2 \%)$ \\
\hline \multicolumn{2}{|c|}{ NISP total y Porcentajes } & 174 & $\begin{array}{c}11 \\
(13,4 \%)\end{array}$ & $\begin{array}{c}8 \\
(9,8 \%)\end{array}$ & $\begin{array}{c}4 \\
(4,9 \%)\end{array}$ & $\begin{array}{c}46 \\
(56 \%)\end{array}$ & $\begin{array}{c}13 \\
(15,9 \%)\end{array}$ & $\begin{array}{c}82 \\
(100 \%)\end{array}$ \\
\hline
\end{tabular}

Tabla 1. Totales de NISP de artrópodos por estructuras arquitectónicas de recuperación.

Table 1. Total NISP of arthropod per architectural structures of recovery.

superficie coloración púrpura.

\section{Determinaciones pedológicas}

La Tabla 5 se presenta como sumario de los resultados obtenidos en el análisis de los sedimentos de las diferentes estructuras muestreadas.

La cantidad de materia orgánica (MO) en el sedimento varía en un rango de pobre (50\%) a extremadamente pobre $(50 \%)$. Los valores más altos fueron determinados en la estructura XI. La concentración de fósforo (P) en las muestras oscila entre bajo (10\%), regular (10\%), alto $(20 \%)$ y muy alto $(60 \%)$. Los valores de potencial Hidrógeno $(\mathrm{pH})$ fluctúan en el rango de la basicidad. Con respecto a los residuos orgánicos, se observa la presencia de albúmina en el $90 \%$ de la muestra total.

En la siguiente figura están representadas las clases texturales, en donde se observa la distribución de las fracciones arena, limo y arcilla, correspondiendo todas las muestras a franco arcillo arenoso, excepto las estructuras VIII, X y XV (donde no se registraron restos materiales) y el testigo de referencia con textura franco arenosa.

\section{Discusión}

Para la cuenca de Antofagasta de la Sierra se presume que hacia los 1000 años AP las aldeas agropastoriles tenían una organización jerárquica, siendo las de Fondo de Cuenca las de mayor desarrollo productivo agrícola, con la incorporación de técnicas de regadío, como Bajo del Coypar y Campo Cortaderas (Olivera y Vigliani 2000/2002; Olivera et al. 2003-2005). Paralelamente, se incrementa la caza junto con un manejo más complejo de los rebaños domesticados, desarrollándose morfotipos especializados orientados a la producción de fibra y al transporte (aumento de la proporción de animales adultos y de gran tamaño). Esto sostendría a sectores diferenciados de la sociedad agropastoril, con el control de la producción textil y mayor práctica caravanera (Olivera y Grant 2008).

Figura 4. NISP\% total de la muestra de vertebrados.

Figure 4. Total \%NISP of the vertebrate sample.

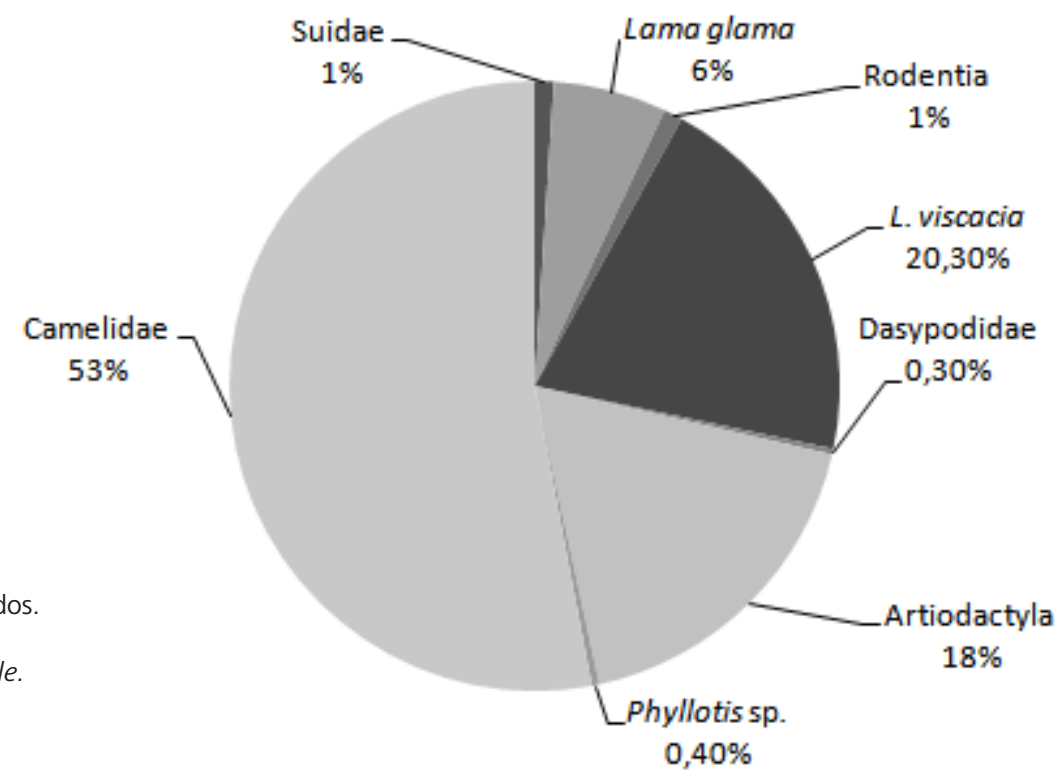




\begin{tabular}{|c|c|c|c|c|c|c|c|c|c|c|c|}
\hline \multicolumn{2}{|c|}{$\begin{array}{l}\text { Estructura/ } \\
\text { Taxón }\end{array}$} & \multirow{2}{*}{$\begin{array}{l}\text { NR } \\
51\end{array}$} & \multirow{2}{*}{$\begin{array}{c}\text { Artyodactila } \\
0\end{array}$} & \multirow{2}{*}{$\begin{array}{c}\text { Camelidae } \\
33\end{array}$} & \multirow{2}{*}{$\begin{array}{l}\text { Lama } \\
\text { glama }\end{array}$} & \multirow{2}{*}{$\begin{array}{c}\text { Rodentia } \\
\text { indet. }\end{array}$} & \multirow{2}{*}{$\begin{array}{c}\begin{array}{c}\text { Lagidium } \\
\text { viscacia }\end{array} \\
0\end{array}$} & \multirow{2}{*}{$\begin{array}{c}\begin{array}{c}\text { Phillotys } \\
\text { sp. }\end{array} \\
0\end{array}$} & \multirow{2}{*}{$\begin{array}{c}\text { Dasypodidae } \\
0\end{array}$} & \multirow{2}{*}{$\begin{array}{c}\text { Suidae } \\
\text { indet. }\end{array}$} & \multirow{2}{*}{$\begin{array}{c}\begin{array}{c}\text { NISP total y } \\
\text { Porcentajes }\end{array} \\
44(5 \%)\end{array}$} \\
\hline \multirow{5}{*}{ 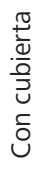 } & II & & & & & & & & & & \\
\hline & $\mathbf{v}$ & 34 & 9 & 0 & 0 & 3 & 18 & 0 & 3 & 0 & $33(4 \%)$ \\
\hline & $\mathbf{X I}$ & 137 & 0 & 0 & 9 & 0 & 106 & 0 & 0 & 0 & $115(14 \%)$ \\
\hline & XIII & 19 & 5 & 0 & 14 & 0 & 0 & 0 & 0 & 0 & $19(2 \%)$ \\
\hline & Subtotal & 241 & 14 & 33 & 23 & 8 & 124 & 0 & 3 & 6 & $211(25 \%)$ \\
\hline \multirow{4}{*}{ 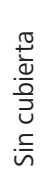 } & III & 92 & 0 & 24 & 0 & 0 & 0 & 0 & 0 & 0 & $24(3 \%)$ \\
\hline & VIII & 467 & 138 & 216 & 26 & 0 & 58 & 4 & 0 & 0 & $442(52 \%)$ \\
\hline & $x$ & 232 & 0 & 174 & 0 & 0 & 0 & 0 & 0 & 0 & $174(20 \%)$ \\
\hline & Subtotal & 791 & 138 & 414 & 26 & 0 & 58 & 4 & 0 & 0 & $640(75 \%)$ \\
\hline \multicolumn{2}{|c|}{$\begin{array}{l}\text { NISP total y } \\
\text { Porcentajes }\end{array}$} & 1032 & $\begin{array}{c}152 \\
(18 \%)\end{array}$ & $\begin{array}{c}447 \\
(52,8 \%)\end{array}$ & $\begin{array}{c}49 \\
(5,8 \%)\end{array}$ & $\begin{array}{c}8 \\
(1 \%)\end{array}$ & $\begin{array}{c}182 \\
(21 \%)\end{array}$ & $\begin{array}{c}4 \\
(0,4 \%)\end{array}$ & $\begin{array}{c}3 \\
(0,3 \%)\end{array}$ & $\begin{array}{c}6 \\
(0,7 \%)\end{array}$ & $\begin{array}{c}847 \\
(100 \%)\end{array}$ \\
\hline
\end{tabular}

Tabla 2. Totales de NISP de vertebrados por estructuras del sitio PC3C.

Table 2. Total NISP of vertebrates for PC3C site structures.

Esta etapa coincidiría con las ocupaciones agropastoriles en las estructuras sin cubierta de PC3-c (ca.1100 y 800 años AP). Luego, desde los 600 años $A P$, mientras que en el sector medio del río Las Pitas los camélidos son aprovechados en una proporción similar a las llamas y vicuñas (Urquiza 2009a), las aldeas de La Alumbrera y El Coyparcito toman el control del tráfico caravanero y de las zonas altas de pastoreo y de producción agrícola (Olivera y Vigliani op. cit.). En PC3-c, hay un hiato ocupacional entre ca. 800 y 370 años AP. Durante la etapa colonial ocurre una fase húmeda (300-100 14C AP) (Olivera y Grant 2008), coincidiendo con la ocupación de los recintos cubiertos de PC3-c como depósitos de alimentos y manufacturas, con la ausencia significativa de vicuñas. Se registra un aumento de recursos, como las pasturas en río Las Pitas, Ilanco, Laguna Antofagasta y Carachipampa (Olivera y Grant 2008).

Las estructuras cubiertas de PC3-c (en falsa bóveda y cistas o pozos) presentan el $23 \%$ de la partes esqueletales animales recuperadas, concentrando el $77 \%$ del total las estructuras sin techo (III, VIII y X). Mientras que para la entomofauna sucede a la inversa, agrupándose un $88 \%$ en las estructuras techadas y sólo un $12 \%$ en las descubiertas, resultado esto, entre otros factores, de la acción eólica.

Las estructuras III, VIII y X son los recintos con mayores dimensiones en el sitio, y sus fechados se ubican entre ca.1100 y 800 años AP. Arquitectónicamente son estructuras sin cubierta, lo que generó que los restos óseos hayan quedado expuestos a la intemperie durante largos periodos, ocasionando que el material haya sido meteorizado, y que en el interior de las recintos crecieran arbustos de Acantholippia hastulata, alterando con sus raíces los vestigios arqueológicos. Estas estructuras poseen actualmente sus muros colapsados, lo que permite la libre circulación por el interior de las mismas de animales que pisotean los materiales arqueológicos, resultando en una de las causas de la alta fragmentación de los restos óseos arqueofaunísticos. Otro agente que causó remoción en la estructura VIII, fue Rodentia, que actuó sobre los restos de Camelidae neonato (costillas y huesos largos). Los recintos III y VIII presentan similares características arquitectónicas. La estructura $X$, en cambio, posee forma de hondonada y sin muros visibles; se encuentra contigua al muro NE de la estructura VIII. Ambas presentan el mayor número de conjuntos esqueletales, en su mayoría camélidos.

\begin{tabular}{ccccccc}
\hline $\begin{array}{c}\text { Estructuras/ Grados de fusión } \\
\text { ósea }\end{array}$ & Sin fusionar & Semifusionado & Fusionado & No observado & $\begin{array}{c}\text { NISP total y } \\
\text { Porcentajes }\end{array}$ \\
\hline \multirow{4}{*}{ Estructuras } & $\mathrm{II}$ & 0 & 0 & 33 & 0 & $33(6,7 \%)$ \\
con cubierta & $\mathrm{V}$ & 0 & 0 & 0 & 0 & $0(0 \%)$ \\
& $\mathrm{XI}$ & 4 & 0 & 2 & 3 & $9(1,8 \%)$ \\
& $\mathrm{XIII}$ & 1 & 1 & 5 & 7 & $14(2,8 \%)$ \\
& Subtotal & $5(8,9 \%)$ & $1(1,8 \%)$ & $40(71,4 \%)$ & $10(17,9 \%)$ & $56(11,3 \%)$ \\
\cline { 2 - 7 } Estructuras & $\mathrm{III}$ & 0 & 11 & 8 & 5 & $24(4,8 \%)$ \\
sin cubierta & $\mathrm{VIII}$ & 61 & 0 & 27 & 154 & $242(48,8 \%)$ \\
& $\mathrm{X}$ & 14 & 8 & 46 & 106 & $174(35,1 \%)$ \\
NISP total y Porcentajes & Subtotal & $75(17,1 \%)$ & $19(4,3 \%)$ & $81(18,4 \%)$ & $265(60,2 \%)$ & $440(88,7 \%)$ \\
\hline
\end{tabular}

Tabla 3. Grados de fusión ósea en especímenes de camélidos por estructuras del sitio PC3-c.

Table 3. Grades of fusion bone in camelid specimens per architectural structures. 


\begin{tabular}{|c|c|c|c|c|c|c|c|}
\hline $\begin{array}{r}\text { Estructuras } \\
\text { meteo }\end{array}$ & $\begin{array}{l}\text { Estadios de } \\
\text { ización }\end{array}$ & 1 & 2 & 3 & 4 & 5 & $\begin{array}{c}\text { Totales y } \\
\text { Porcentajes }\end{array}$ \\
\hline \multirow{5}{*}{$\begin{array}{l}\text { Estructuras } \\
\text { con cubierta }\end{array}$} & Estructura II & 21 & 15 & 14 & 2 & - & $52(5 \%)$ \\
\hline & Estructura V & 11 & 11 & 7 & 5 & - & $34(3,2 \%)$ \\
\hline & Estructura XI & 31 & 27 & 79 & - & - & $137(13,4 \%)$ \\
\hline & Estructura XIII & 6 & 3 & 1 & 1 & 8 & $19(2 \%)$ \\
\hline & Subtotal & $69(6,7 \%)$ & $56(5,4 \%)$ & $101(9,7 \%)$ & $8(0,8 \%)$ & $8(0,8 \%)$ & $242(23,6 \%)$ \\
\hline \multirow{4}{*}{$\begin{array}{l}\text { Estructuras sin } \\
\text { cubierta }\end{array}$} & Estructura III & 9 & 7 & 16 & 4 & 57 & $93(9 \%)$ \\
\hline & Estructura VIII & 41 & 233 & 96 & 97 & - & $467(45,2 \%)$ \\
\hline & Estructura X & 10 & 34 & 70 & - & 118 & $232(22,4 \%)$ \\
\hline & Subtotal & $60(5,8 \%)$ & $274(26,5 \%)$ & $182(17,6 \%)$ & $101(9,7 \%)$ & $175(16,9 \%)$ & $792(76,6 \%)$ \\
\hline \multicolumn{2}{|c|}{ Totales y Porcentajes } & $\begin{array}{c}129 \\
(12,5 \%)\end{array}$ & $\begin{array}{c}330 \\
(32 \%)\end{array}$ & $\begin{array}{c}283 \\
(27 \%)\end{array}$ & $\begin{array}{c}109 \\
(10,5 \%)\end{array}$ & $\begin{array}{c}183 \\
(18 \%)\end{array}$ & $\begin{array}{c}1034 \\
(100 \%)\end{array}$ \\
\hline
\end{tabular}

Tabla 4: Estadios de meteorización de vertebrados por estructuras (sensu Behrensmeyer 1978)

Table 4: Stages of weathering of vertebrate per structures (sensu Behrensmeyer 1978).

Es probable que la hondonada fuera aprovechada para depositar los desechos consumidos en el recinto VIII. Esta morfología y la ausencia de muros posibilitaron en las capas superficiales una circulación de líquidos en sentido vertical y horizontal, lo que ocasionó que el pH sea menos alcalino $(7,70)$ que en el resto de las estructuras. Para el fondo de la hondonada, al ser baja la potencia estratigráfica del sitio PC3-c, la roca madre de la peña se encuentra inmediata a la capa 2. Esta situación provocaría un drenaje restringido impidiendo el lavado de todo elemento soluble, encharcando los sedimentos y huesos en diferentes momentos resultando esto en un alto grado de meteorización para la muestra ósea. esto a espículas de carbón, cenizas y tiestos tiznados, registrados en planta en los recintos.

Las estructuras II, V, XI y XIII, fechadas entre ca.370 a 100 años AP, son arquitectónicamente cerradas, con una cubierta abovedada de ignimbrita; por estas características los materiales recuperados en su interior no estuvieron expuestos a la intemperie ni a otros factores ambientales. Al igual que las estructuras sin cubierta, la XI registra un alto número de vertebrados, correspondiendo el mayor porcentaje a dos individuos de $L$. viscacia y a un camélido neonato con golpes intencionales en la superficie ósea. Esta estructura contiene el mayor número de partes
Con respecto al aprovechamiento de los recursos faunísticos por agentes humanos en las estructuras sin cubierta, $y$ en función de la obtención de los parámetros estadísticos PAR e IAR, se observa la utilización del recurso Camelidae, en forma de individuos jóvenes y adultos, en los recintos III y X, y de neonatos (con alteraciones térmicas) en la estructura VIII. La muestra exhibe una selección de cortes con abundante carne para su consumo; miembros traseros y costillar, como así también la selección de animales silvestres y pequeños complementarios a la dieta. Estos tres recintos, al no tener cubierta, presentan condiciones favorables para el flujo de aire y uso de fogones, y son los únicos que presentan huesos con alteraciones térmicas (97\%), sumado

Figura 5. Diagrama de clases texturales de suelo, discriminadas por estructuras arquitectónicas.

Figura 5. Textural classes diagram of soil, discriminated per architectural structures

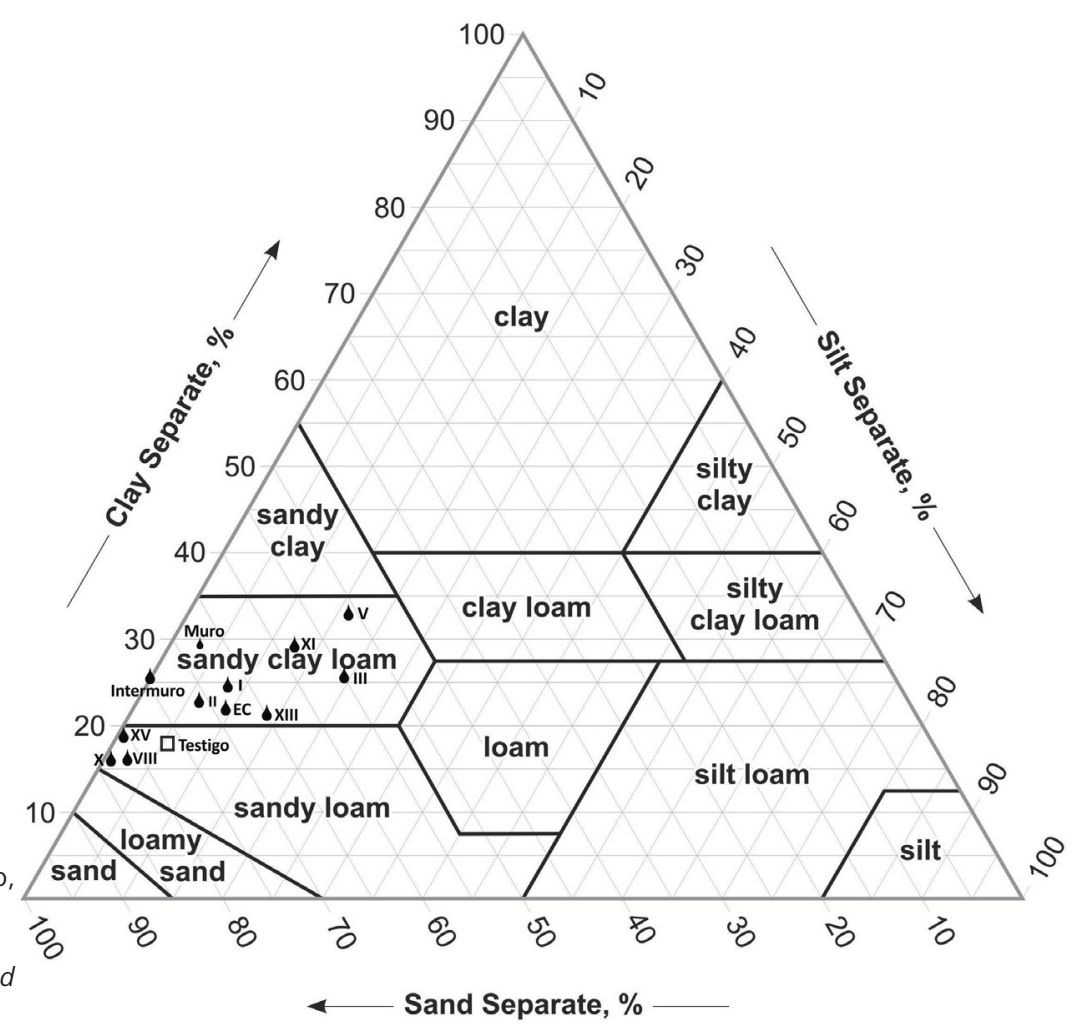




\begin{tabular}{cccccccccccc}
\hline $\begin{array}{c}\text { Determinaciones químicas / } \\
\text { Estructuras }\end{array}$ & EC & II & III & V & VIII & X & XI & XIII & XV & testigo \\
\hline pH & 7,25 & 8,18 & 9,05 & 8,42 & 8,02 & 7,75 & 8,60 & 8,04 & 7,92 & 8,47 \\
ALB & + & + & + & + & + & + & + & + & + & - \\
P & 2 & 5 & 5 & 4 & 5 & 5 & 5 & 5 & 4 & 3 \\
MO & P & EP & EP & P & EP & EP & P & P & P & EP \\
\hline
\end{tabular}

Tabla 5. Determinaciones químicas de los sedimentos del sitio PC3-c. pH: potencial Hidrógeno: neutro (6,6-7,3), medianamente básico (7,4-7,8), básico (7,9-8,4), ligeramente alcalino (8,5-9); ALB: albúmina: (+) presencia (-)ausencia; P: Fósforo: bajo(2); regular(3); alto(4); muy alto(5); MO: Materia orgánica: EP: extremadamente pobre (0,00-0,60\%), P: pobre(0,61-1,20\%).

Table 5. Chemical determinations of sediments PC3-c site. pH: potential Hydrogen: neutral (6.6 to 7.3), fairly basic (7.4 to 7.8), basic (7.9 to 8.4), slightly alkaline (8.5 to 9); ALB : albumin: (+) presence (-) absent, P: Phosphorus: low (2), regularly (3), high (4), very high (5), MO: Organic matter: EP: extremely poor (0.00-0.60\%), P: poor (0.61 to $1.20 \%)$.

esqueletales enteras y articuladas. La muestra presenta valores bajos de meteorización ósea y una muy buena conservación, habiéndose preservado un fragmento de cuero curtido y recortado de Camelidae, así como restos de uñas, dientes, tejidos y pelos de $L$. viscacia. Diferentes partes esqueletales de las vizcachas muestran marcas de roedores y de carnívoros, y una diáfisis se encuentra pulida. Por el tipo de marcas registradas, y la ausencia de cuevas de roedores, la perturbación registrada podría deberse a la acción de carnívoros medianos como zorros o perros, los que habrían aprovechado este recinto de acotadas dimensiones y protegido para el consumo de sus presas y/o el ingreso de restos óseos. A la vez, la circulación de rebaños sobre la peña ha podido ingresar el material osteológico a la estructura. En cuanto a la alteración de la estructura, y sumado a la perturbación animal mencionada, se debe referir la reutilización por parte de la abuela del actual propietario (Don Ernesto Morales) quién la utilizó como repositorio de lanas y vellones de oveja, algunos recuperados en la excavación junto con un resto de tela industrial del recinto XI (Cohen 2011).

El resto de las estructuras con cubierta y de pequeñas dimensiones (II, V y XIII), presentan un menor número de restos arqueofaunísticos, y solamente en la $V$ se recuperaron huesos termoalterados, aunque en bajo porcentaje (3\%). En relación al aprovechamiento de los recursos animales, las estructuras II y XIII presentan huesos largos de camélidos, principalmente tibias. Las marcas antrópicas, cortes y golpes, sobre los restos óseos en Lama glama y las concreciones de $\mathrm{NaCl}$, sugieren el ingreso de estas partes anatómicas de fácil transporte para su consumo, ya faenadas y deshidratadas para su conservación (charki?). Exclusivamente en el recinto II, fechado en $332 \pm 44$ años $A P$, se evidencia el consumo de Suidae, animal que fue introducido en épocas de contacto hispano-indígena. En la estructura $V$ con un fechado de 128+32 años AP se observa una preferencia por L.viscacia neonato, encontrándose marcas de golpe y cortes con instrumentos filosos en distintas partes anatómicas (costilla, pelvis y tibias); asociado a este roedor se registraron placas de Dasypodidae, sin evidencias que sugieran su consumo. En estas estructuras, los rasgos arquitectónicos y los valores alcalinos del pH del sedimento han favorecido la conservación tanto de vertebrados como invertebrados. En el recinto XI el pH básico $(8,60)$, generó que la muestra se encuentre en buen estado y presente precipitaciones de sales en la superficie de los huesos, indicando variaciones de humedad en esta estructura.

En cuanto a la entomofauna, se preservan en el recinto $\mathrm{XI}$ exoesqueletos de Curculionidae, alas de Anisoptera, pupas de Díptera y en el caso de los tenebriónidos algunos se encuentran articulados (cabeza, tórax y patas). La capa 2 en las estructuras XIII y XI, debió depositarse en primavera/verano puesto que se encontraron anisópteros, y en la XI éstos se asocian a un neonato de Camelidae. Anisoptera se caracteriza por vivir en las inmediaciones de lagos y ríos, y ha sido recuperado anteriormente en contextos arqueológicos de sitios cercanos al río Las Pitas (Urquiza 2009a).

En el caso de las estructuras II y $\mathrm{V}$, sus muros y techos se encuentran colapsados hacia el interior y se hallaron restos de cerámica tosca en el exterior e interior de la estructura V. En esta remoción han debido contribuir la acción antrópica y animal. La estructura II registra cuevas de roedores, en tanto que la estructura $V$ presenta un número acotado de artrópodos (pupas) y marcas de carnívoros medianos y roedores sobre el conjunto óseo. Estos agentes pudieron contribuir al desplazamiento de los materiales arqueológicos y de artrópodos hacia adentro y afuera de la estructura. En el caso de la estructura XIII, el registro se encuentra perturbado debido a la acción de roedores oportunistas, y por la reutilización del recinto en épocas recientes, evidenciado en diversos materiales, como por ejemplo un retazo de tela industrial y una hoja metálica de cuchillo. En las estructuras II y XIII se encontraron especies vegetales "recolectables", como fragmentos de vaina de Hoffmanseggia eremophila y endocarpos de las variedades Prosopis nigra, aff flexuosa, sp., Fabaceae mimosoidea. Este último ejemplar es alóctono a Antofagasta de la Sierra, siendo propio de zonas de valle (Aguirre 2010, en Cohen 2011). Estos vegetales explican la presencia de Curculionidae localizada generalmente en depósitos de vegetales 
(Urquiza 2010). Algunos curculiónidos pueden provenir de cotas más bajas, si hubieran sido trasladados junto a la flora alóctona. En las estructuras II, XI y XIII, los restos vegetales se asocian con partes esqueletales en diferentes estadios de descomposición y a artrópodos oportunistas como Tenebrionidae y Anisoptera, los que pudieron alimentarse de Curculionidae y Diptera en sus primeras fases de desarrollo (huevos, larvas o pupas). En la estructura XIII, los restos de vertebrados (huesos, tejido muscular y cartilaginoso) se vinculan con vellones, lana, cordeles, vegetales y restos de sal $(\mathrm{NaCl})$ algunos adheridos a curculiónidos, sugiriendo el posible resguardo de objetos y comida en esta estructura.

Como se pudo observar, las estructuras sin cubierta poseen el mayor número de vertebrados. En el caso de los restos de invertebrados sucede lo contrario, el mayor número de artrópodos se presenta en las estructuras arquitectónicamente cerradas, y en los recintos sin cubierta se encontraron solo pupas aisladas. En estos últimos, posiblemente la entomofauna ha sido transportada hacia otros lugares como consecuencia del viento. Otros factores, como el desplazamiento por agua de lluvia, el paso de personas y/o animales, y la meteorización química de los exoesqueletos pudieron condicionar negativamente el registro entomológico.

Los estudios geoquímicos permitieron realizar inferencias sobre la conservación diferencial de los restos arqueofaunísticos de las estructuras, y realizar comparaciones con los sitios arqueológicos del área. Las determinaciones de materia orgánica dieron como resultado lo esperable para un ambiente, árido y desértico como el de Antofagasta de la Sierra, sometido a escasas lluvias, con gran radiación solar y alternancias de temperatura entre el día y la noche, lo que genera que el suelo no contenga una cantidad importante de carbono orgánico. Sin embargo, al hacer una comparación entre las estructuras observamos que los valores más altos de materia orgánica se encuentran en las estructuras más pequeñas y con cubierta ( $\mathrm{V}, \mathrm{XI}, \mathrm{XIII}, \mathrm{XV}$ y EC), indicando que algunos agentes faunísticos, antrópicos o ambientales (como el viento), pudieron arrastrar el guano de los animales hacia estas estructuras, quedando atrapado en muros y techos. Como mencionamos, la potencia estratigráfica del sitio PC3-c es reducida, por lo que los valores básicos de $\mathrm{pH}$ derivarían de la roca madre rica en álcalis, que dio origen al suelo.

En cuanto a los residuos orgánicos, todas las estructuras excepto la muestra testigo, presentaron albúmina -proteína animal que se encuentra en el plasma sanguíneo- indicando que los sedimentos actuaron de matriz contenedora de sangre y/o carne, lo que se corrobora con los restos faunísticos asociados, que debieron ser depositados con restos cárnicos.

La estructura $\mathrm{XV}$, sin registro de vestigios materiales, presenta altos valores de albúmina, fósforo y materia orgánica. Por lo que, al igual que el resto de las estructuras de PC3-c, muestra evidencias de actividades humanas, pudiendo relacionarse con un lugar de matanza de animales. No ha sido relacionado con un corral ya que los sedimentos con guano se caracterizan por porcentajes bajos de albúmina y altos en ácidos grasos asociados a un pH básico (Urquiza 2010). Los sedimentos pertenecientes a la capa 2 habrían capturado la mayor concentración de residuos y agregados generados por la actividad antrópica en las estructuras. La EC se encuentra hacia el sur, al borde de la peña, y tampoco presenta restos materiales. Los valores de albúmina son altos, y moderados los de materia orgánica; y a diferencia de las demás estructuras, el valor de $\mathrm{pH}$ es neutro, y la presencia de fósforo es menor a la del testigo. Los propietarios actuales de la localidad comentaron que los bordes de la peña y las rocas que pudieron funcionar de muro en la EC, fueron barreteados de modo que la piedra cayera al pie del farallón para ser empleada en el pircado de corrales modernos (Cohen 2011; Ortiz 2011). Al derribar el muro y parte de la roca madre que pudo actuar de piso ocupacional, generó que el drenaje de fluidos no se encuentre restringido, permitiendo el lavado de algunos elementos químicos y vestigios arqueológicos. Los valores de albúmina se asignarían a restos animales contenidos el muro antes de ser destruido, ya que la práctica de construir los muros y colocar partes de animales en su interior fue observado en otras estructuras de PC3-c, y en el área en la actualidad.

Los suelos de las estructuras analizadas son francos. Se distingue el predominio de la fracción arena en todas las muestras sedimentarias de PC3-C, con texturas moderadamente gruesas en las estructuras VIII, X y el testigo de referencia, mientras que en el resto es moderadamente fina, lo que es coherente con el ambiente desértico y las condiciones eólicas del área de estudio. La erosión eólica tiende a actuar eliminando ante todo, la fracción limo, por ser más fina que la arena y más erodable que la arcilla, dado que no posee la característica cohesión entre partículas que tiene esta última. En el triángulo de textura (Figura 6) se observa que la muestra testigo se ubica en la clase franco arenosa la cual posee menos del $20 \%$ de arcilla, y presenta semejanzas a las distribuciones de texturas de las estructuras VIII, X y XV, con la diferencia que en los recintos $X$ y $X V$ el limo es prácticamente inexistente. Estas muestras señalan una proporción extrema de una cantidad de arena y muy baja proporción de arcilla, que son normales en los suelos de desiertos. El resto de las estructuras (III, V, XI, XIII, EC) presentaron material arcilloso adherido sobre la roca madre, lo que pudo ocasionar un pequeño aumento de esta fracción en las muestras (Ortiz 2011).

\section{Consideraciones finales}

La sinergia entre los datos faunísticos y geoquímicos de los contextos depositacionales asociados, aportó evidencias 
zooarqueológicas, tafonómicas y económicas de los grupos agropastoriles en las estructuras del Tardío-Inca para PC3-C.

Coincidimos con Cohen (2011) en que las estructuras de pircado y hondonada se vinculan a prácticas residenciales con procesamiento y consumo de alimentos; también en que las estructuras en falsa bóveda y cista o pozo se asocian a depósitos, sin embargo no encontramos hasta el momento evidencia que respalde que estas contengan contextos funerarios.

En las estructuras sin cubierta, ca. 1100-800 años AP, se habrían desarrollado actividades múltiples, vinculadas a prácticas de procesamiento y consumo de alimentos, con el uso de fogones y áreas de descarte. Se distingue el aprovechamiento de partes de alto rinde económico de camélidos domesticados (Lama glama) jóvenes, adultos y en menor medida neonatos, lo que sugiere el traslado de ciertas partes anatómicas para su consumo diferido. Complementando la dieta, han sido aprovechados los roedores silvestres (L.viscacia). Estos restos animales se asocian a exoesqueletos de Tenebrionidae, oportunista que se habría alimentado de carcasas animales, vegetales y de restos de otros atrópodos depositados en el interior de las estructuras. Luego se vislumbra un hiatus ocupacional hasta 370 años AP, cuando en las estructuras cubiertas se evidencia el consumo de L. viscacia, junto con partes de bajo rinde cárnico, como patas y cara de animales exóticos (Suidae) y de alto rendimiento económico, como los cuartos traseros de camélido. La preferencia por el faenamiento de camélidos domesticados y los excedentes asociados al procesamiento secundario (cueros, cordeles, vellones), refieren un cómodo acceso y manejo del ganado autóctono, utilizado no sólo en la dieta sino como transporte, como recurso de intercambio y para la fabricación de artefactos.

Los recintos cubiertos contienen un mayor número de artrópodos (Curculionidae, Tenebrionidae y Calliphoridae) asociados con restos de vegetales y de vertebrados, junto a concreciones de sal, lo que permite inferir almacenamiento de alimentos. La presencia de neonatos y odonatos indica la época estival, correspondiéndose con el movimiento de los rebaños de camélidos para pastar, los que en épocas de lluvia son movilizados a las vegas de zona intermedia, y al curso inferior del río Las Pitas. La estructura XIII, ca. 194 años AP, presenta momentos de ocupación como depósito de animales y vegetales; posteriormente es abandonada hasta principios del siglo $\mathrm{XX}$, donde es reutilizada como depósito de lanas, cordeles y textiles por la abuela de los actuales propietarios y es eventualmente visitada por carnívoros y roedores. Es posible que en estos momentos, los habitantes de Peñas Coloradas ocuparan como puestos estacionales los recintos localizados en la zona baja de la peña, utilizando como depósitos los pequeños recintos cubiertos sobre el farallón. Esta ocupación se relaciona con el sector inferior de la peña, a espacios productivos de caza y pastoreo, y de cultivo de vegetales (lo que por otra parte se observa actualmente), y a la vez se vincula al arte rupestre de PC3, con representaciones de camélidos asignadas al Formativo temprano (Podestá 1990). Sin embargo, aún quedan por excavar estructuras en el sitio y en PC3 (bajo) lo que brindará mayores datos sobre las actividades de los pobladores prehispánicos del lugar.

Se distingue una continuidad de las actividades de caza a lo largo del tiempo (Aschero 2010; Elkin 1996; Escola 2002; Urquiza 2009a). La caza de L.viscacia se evidencia en el área hacia el 9700 AP (Elkin 1996), pero su representación es baja en el tardío de la cuenca media del río Las Pitas, donde es notable la especialización en la caza de vicuñas con un aprovechamiento completo del recurso (Urquiza op.cit.). En la secuencia de PC3c, al igual que para otros sitios de Las Pitas, la economía es mixta, con pastoreo de camélidos y mantenimiento de la caza y recolección. Si bien la zona de emplazamiento del sitio PC3-c presenta ventajas aprovechables para las actividades de caza y pastoralismo, hay una preferencia por L.viscacia y no se registran camélidos silvestres (vicuña).

En relación a la tafonomía, y más allá de los modelos tafonómicos generales para el área, hay que tener cuidado con las extrapolaciones directas a nivel intersitio de procesos físico químicos/biológicos/antrópicos, y establecer en detalle la historia tafonómica de cada sitio en particular y a su vez de cada estructura. La información geoquímica demostró un uso intenso durante momentos Tardíos-Incas principalmente en lo referido al procesamiento del recurso animal, en todas las estructuras analizadas, tanto en aquellas que presentaban vestigios arqueológicos como en las que no. Esto ratifica la validez de la geoquímica, en función de la comparación de estos datos con aquellos obtenidos de la muestra testigo. Es interesante en este sentido, que las estructuras EC y XV, sin registros materiales, brindaran elementos químicos producto de actividades humanas y animales. A la vez que aportaron al entendimiento tafonómico del sitio en general.

Por su ubicación clave, diferentes autores indican a PC3 como un sitio de enlace para las interacciones económicas entre las distintas zonas altitudinales (Olivera y Podestá 1993, Podestá 1988, Podestá et al. 1991). Situación que habría continuado en momentos tardíos-incas, con relaciones e intercambios entre los pisos altitudinales de Las Pitas y otras regiones altitudinalmente más bajas (valles). En este intercambio habrían sido fundamentales los recursos económicos, aunque se reconoce que gran parte habría sido intangible (simbólicos, información, etc). Finalmente en $\mathrm{PC} 3-\mathrm{C}$ han quedado registradas múltiples actividades, tanto de índole doméstica como para el resguardo de objetos o alimentos. Algunas de estas prácticas se arraigaron en los pobladores locales, 
como la reutilización de las estructuras como depósitos.

San Miguel de Tucumán, Septiembre de 2012

\section{Agradecimientos}

Especialmente a la Dra. Lorena Cohen por invitarnos a las excavaciones y facilitarnos el material de estudio. Agradecemos a la Geól. Patricia Cuenya y la Mg. Susana Aranda por la buena predisposición en las consultas. Por último, nuestro reconocimiento a los evaluadores por sus aportes que ayudaron a mejorar el manuscrito. Este trabajo se llevó a cabo en el marco de los proyectos FONCyT (PICT 2010-1160), CIUNT (26/G404) y CONICET (PIP 464).

\section{Bibliografía}

Aschero, C. A. 1999. El arte rupestre del desierto puneño y el noroeste argentino. En: Arte Rupestre en los Andes de Capricornio: 97-135. Santiago de Chile, Museo Chileno de Arte Precolombino.

Aschero, C. A. 2000. Figuras humanas, camélidos y espacios en la interacción circumpuneña. Arte en las rocas. Arte rupestre, menhires y piedras de colores en Argentina (ed. por M. M. Podestá y M. de Hoyos), pp. 15-44. Sociedad Argentina de Antropología, AINA, Buenos Aires.

Aschero, C. A. 2006. De cazadores y pastores. El arte rupestre de la modalidad Río Punilla en Antofagasta de la Sierra y la cuestión de la complejidad en la Puna meridional argentina. Tramas en la Piedra. Editado por D. Fiore y M. Podestá. pp 103-140. Buenos Aires.

Aschero, C. A. 2010. Arqueologías de Puna y Patagonia centro-meridional: comentarios generales y aporte al estudio de los cazadores-recolectores puneños en los proyectos dirigidos desde el IAM (1991-2009).En: Rastros en el camino...Trayectos e Identidades de una Institución. Editado por C. Aschero, P. Arenas y C. Taboada, EDUNT. San Miguel de Tucumán.

Barba, L., R .Rodríguez y J. Córdova. 1991. Manual de Técnicas Microquímicas de Campo para la Arqueología. UNAM, México.

Behrensmeyer, A. K. 1978. Taphonomic and ecological information from bone weathering. Paleobiology 4 (2): 150-162.

Binford, L.R. 1981. Bones. Ancient men and modern miths. Academic press. New York.

Bouyoucos, G.J. 1962. Hydrometer method improved for making particle size analysis of soil. Agronomy Journal 54:464-465.
Brain, C. K. 1981. The Hunters or the Hunted? The University of Chicago Press, Chicago.

Cabrera, A. L. 1976. Territorios fitogeográficos de la República Argentina. Enciclopedia Argentina de Agricultura y Jardinería 2: 1-85.

Cohen, M. L. 2009a. Perspectivas espaciales desde el sitio Peñas Coloradas 3 cumbre (PC3-c) Antofagasta de la Sierra Catamaca. En: Arqueometría $1^{\circ}$ Congreso Latinoamericano y $2^{\circ}$ Nacional de Arqueometría, Vol II, 477-488.

Cohen, M. L. 2009b. Fotografías y algo más... Imágenes de Antofagasta en 1923 como aporte para el planteo de hipótesis y la búsqueda de evidencias contrastadoras. En: Libro de Resúmenes de las IX Jornadas de comunicaciones de la Facultad de Ciencias Naturales e I. M. L. y $2^{\circ}$ Interinstitucional Facultad- Fundación Miguel Lillo-Serie Monográfica y Didáctica Volo 48; pp 109.

Cohen, M. L. 2010. Oculto pero señalado. Sobre la presencia de un bloque con representaciones rupestres y su influencia en la interpretación de un paisaje construido. Libro de resúmenes VIII SIAAR. pp 211-215.

Cohen M. L. 2011 “Prácticas sociales, estrategias de visibilidad y construcción de la cartografía social durante el lapso de ca 1000-500 años AP, en Antofagasta de la Sierra, Catamarca. Perspectivas desde el sitio Peñas Coloradas 3 cumbre". Tesis Doctoral. Facultad de Filosofía y Letras. UBA.

Elkin, D. 1996. "Arqueozoología de Quebrada Seca 3: indicadores de subsistencia humana temprana en la Puna Meridional Argentina". Tesis Doctoral. Facultad de Filosofía y Letras. Universidad de Buenos Aires.

Escola, P. S. 2002 Caza y pastoralismo: un reaseguro para la subsistencia. Relaciones de la Sociedad Argentina de Antropología XXVII: 233-245.

Gifford, D.P.1981. Taphonomy and paleoecology: a critical review of archaeology's sister disciplines. In: Schiffer, ed., Advances in Archaeological Method and Theory 4:365-438.

Grant, J. 2008. "El recurso Camelidae en sitios de Antofagasta de la Sierra (Puna Meridional Argentina) una aproximación osteométrica". Tesis de Licenciatura. Facultad de Filosofía y Letras, Universidad de Buenos Aires.

Gutiérrez, M. A. 2004. "Análisis tafonómicos en el Área Interserrana (Provincia de Buenos Aires)". Tesis Doctoral. Facultad de Ciencias Naturales y Museo, Universidad Nacional de La Plata, La Plata. 
Huelsbeck, D. R. 1991. Faunal remains and consumer behavior: what is being measured? Historical Archaeology 25: 62-76.

Izeta, A.D. 2004. "Zooarqueología del sur de los valles Calchaquíes. Estudio de conjuntos faunísticos del Período Formativo". Tesis Doctoral. Facultad de Ciencias Naturales y Museo. UNLP. Buenos Aires

Izeta, A. 2007 Zooarqueología del sur de los valles Calchaquíes (Provincias de Catamarca y Tucumán, República Argentina): Análisis de conjuntos faunísticos del primer milenio A.D. BAR International Series S1612, John \& Erica Hedges Ltd., Oxford.

Kent, J. D.1982. "The domestication and exploitation of the South American camelids: methods of analysis and their application to circum-lacustrine archaeological sites in Bolivia and Peru". Unpublished Ph. D. Dissertation. Washington University. St. Louis, Missouri, USA.

Kaufmann, C.A. 2009. Estructura de edad y sexo en guanaco: estudios actualísticos y arqueológicos en Pampa y Patagonia. Sociedad Argentina de Antropología. Tesis doctorales de la SAA. $1^{\circ}$ edición, Buenos Aires.

Lyman, R.L.1994. Vertebrate Taphonomy. Cambridge Manuals in Archaeology. Cambridge University Press, Cambridge.

Mengoni Goñalons, G.L. 1988. Análisis de materiales faunísticos de sitios arqueológicos. Xama I, pp 71-120. Mendoza, Argentina.

Mengoni Goñalons, G. L. 1999. Cazadores de guanacos de la estepa patagónica. Sociedad Argentina de Antropología, Buenos Aires. 281 pp.

Mondini, N. M. 2002. Carnivore taphonomy and the early human occupations in the Andes. Journal of Archaeological Science 29: 791-801.

Mondini, N. M. 2003. "Formación del Registro Arqueofaunístico en Abrigos Rocosos de la Puna Argentina. Tafonomía de carnívoros". Tesis Doctoral. Facultad de Filosofía y Letras, UBA. Buenos Aires.

Mondini, N. M. 2004. Magnitude of faunal accumulations by carnivores and humans in the South American Andes. En: T. P. O'Connor (ed.), Biosphere to Lithosphere: New Studies in Vertebrate Taphonomy, Proceedings of the 9th Conference of the International Council of Archaeozoology, Oxbow Books, Oxford, pp. 16-24.

Mondini, M. 2007. Tafonomía de vertebrados en la Puna argentina: atrición y modificaciones óseas por carnívoros. In: Human and Faunal Relationships
Reviewed: An Archaeozoological Approach (ed. by E. Corona-M. and J. Arroyo-Cabrales ), pp. 95-112. BAR (British Archaeological Reports), International Series, BAR S1627, Oxford.

Nasti, A.1991. Tafonomia de vertebrados en contextos sedimentarios modernos de la Puna Sur chances de enterramiento y formación del registro arqueológico. Shincal 1 pp 231-251.

Nasti, A.1995. Desarticulación natural y supervivencia de partes anatómicas: Tafonomía de vertebrados modernos en medioambientes puneños. Palimpsesto, Revista de Arqueología 4: 70-90.

Nicholson, R.1993. A morphological investigation of burnt animal bone and an evaluation of its utility in archaeology. Journal of Archaeological Science 20: 411428.

Olivera, D.1989. Prospecciones arqueológicas en Antofagasta de la Sierra (Puna Argentina), Pcia. de Catamarca: Informe Preliminar. Shincal 1: 7-23.

Olivera, D. 1992. "Tecnología y estrategias de adaptación en el Formativo (Agroalfarero Temprano) de la Puna Meridional Argentina. Un caso de estudio: Antofagasta de la Sierra (Prov. de Catamarca, R.A.)". Tesis de Doctorado, Facultad de Ciencias Naturales y Museo. UNLP, Buenos Aires.

Olivera, D.1997. La importancia del recurso Camelidae en la Puna de Atacama entre los 10000 y 500 años A.P. Estudios Atacameños 14: 29-41.

Olivera, D. E. y D. C. Elkin 1994. De cazadores y pastores: el proceso de domesticación en la Puna meridional argentina. Zooarqueología de Camélidos 1:95-124.

Olivera, D. y J. Grant. 2008. Economía y Ambiente durante el Holoceno Tardío (ca. 4500-400) de Antofagasta de la Sierra (Puna Meridional Argentina). En Temas de Arqueología: Estudios tafonómicos y zooarqueológicos (1), compilado por A. Acosta, D. Loponte y L. Mucciolo, pp. 99-131.

Olivera, D. y M. Podestá.1993. Los recursos del arte: arte rupestre y sistemas de asentamiento-subsistencia formativos en la Puna Meridional Argentina. Arqueología 3: $93-141$.

Olivera, D.E.y S. Vigliani. 2000-2002. Proceso cultural, uso del espacio y producción agrícola en la Puna meridional argentina. Cuadernos del INAPL 19: 459-481.

Olivera, D; Vigliani, S.; Elías, A.; Grana, L. y P. Tchilinguirian.2003-2005. La ocupación Tardía-Inka en la Puna Meridional: el sitio Campo Cortaderas. Cuadernos 
del INAPL 20:257-278. Bs. As.

Ortiz, J.G. 2010. Análisis físico-químicos de los sedimentos hallados en el Sitio Peñas Coloradas 3 Cumbre. Antofagasta de la Sierra, Catamarca. Argentina. Informe de Práctica de Campo 4, Facultad de Ciencias. Naturales e IML .Univ. Nacional de Tucumán.Ms.

Ortiz, J.G. 2011. "Tafonomía y Procesos de Formación en el sitio Peñas Coloradas 3- cumbre. Antofagasta de la Sierra, Catamarca, Argentina) para el lapso ca. 1000-400 años AP". Tesis de grado. Facultad de Ciencias. Naturales e IML .Univ. Nacional de Tucumán.

Podestá, M. 1990. Región de Antofagasta de la Sierra (Pcia. de Catamarca) Sitio Peña Colorada 3. Informe de Beca CONICET posdoctoral. Ms.

Reigadas, M.C. 1992. La punta del ovillo: Determinación de domesticación y pastoreo a partir del análisis microscópico de fibras y folículos pilosos de camélidos. Arqueología 2: 9-52.

Reigadas, M.C. 1994. Caracterización de tipos de camélidos domésticos actuales para el estudio de fibras arqueológicas en tiempos de transición y consolidación de la domesticación animal. Zooarqueología de camélidos 1, D. Elkin, C. Madero, G. Mengoni, D. Olivera, M. del C. Reigadas y H. Yacobaccio (Eds.), pp. 125-154, Buenos Aires.

Reigadas, M.C. 1995. Criterios metodológicos para la detección del proceso de domesticación de camélidos en el NOA a partir del análisis microscópico de fibras y cueros arqueológicos. Cuadernos 5: 151-168.

Reigadas, M.C. 2008. Explotación de recursos animales y producción textil durante el holoceno en Antofagasta de la Sierra. Estudios Atacameños 35: 35-48.

Reitz, E. J. y E. S. Wing .1999. Zooarchaeology. Cambridge Manuals in Archaeology. Cambridge University Press, Cambridge.

Santoro, C. y L. Núñez. 1987. Hunters of the dry Puna and the salt Puna in the Northern Chile. Andean Past 1: 57-109.

Troll, C. 1958. Las culturas superiores andinas y el medio geográfico. Publicaciones del Instituto de Geografía 5:355, Facultad de Letras, Universidad Nacional Mayor de San Marcos. Lima, Perú.

Urquiza, S.V. 2004. Zooarqueología de ocupaciones tardías del alero Punta de la Peña 4, Antofagasta de la Sierra, Prov. Catamarca. I Jornadas Científicas con fines de Extensión Social. CD. San Pedro de Colalao, Tucumán.
Urquiza, S.V. 2007. Unidades cuantitativas en arqueozoología: mecanismos para la interpretación de procesos naturales y culturales. Primeras Jornadas de Jóvenes Investigadores UNT- AUGM. Formato CD. Universidad Nacional de Tucumán.

Urquiza, S.V. 2009a "Arqueofaunas del Alero Punta de la Peña 4: Implicaciones para el Manejo del Recurso Camelidae en Antofagasta de la Sierra, Puna Austral, Catamarca". Tesis Doctoral. Universidad Nacional de Tucumán.

Urquiza, S.V. 2009b. Zooarqueología de Economías Agropastoriles (1100 a 400 años AP) en la Puna Austral de Argentina En: Serie Monográfica y Didáctica. Vol. $n^{\circ}$ 48. pp. 141. Facultad de Ciencias Naturales e IML. UNT. Tucumán, Argentina.

Urquiza, S.V. 2010. Entomología y Química en el Contexto Arqueológico: Nuevos Elementos para el Entendimiento de la Historia Tafonómica del Registro Arqueofaunístico en Antofagasta de la Sierra, Catamarca. pp 429-437. En: Zooarqueología a principios del siglo XXI: aportes teóricos, metodológicos y casos de estudio, editado por M. De Nigris, P. M. Fernández, M. Giardina, A. F. Gil, M. A. Gutiérrez, A. Izeta, G. Neme y H. D. Yacobaccio. Ed. Libros El Espinillo. Buenos Aires.

Urquiza, S.V.; A.L. Echevarría y R. Lobo Allende. 2009b. Las Plumas en Contextos Arqueológicos de Antofagasta de la Sierra, Catamarca, Argentina. XIII Reunión Argentina de Ornitología. Pp.126. Tafí del Valle, Tucumán.

Urquiza, S.V. y C.A. Aschero.2006. Avances en el estudio del recurso Camelidae: sitio Punta de la Peña 4, Antofagasta de la Sierra, provincia de Catamarca. Actas del IV Congreso Mundial sobre Camélidos, D. Olivera, M. Miragaya y S. Puig (Eds.), pp. 364-368. Santa María (Catamarca), Argentina.

Urquiza S.V., A.S. Romano y S.M.L. López Campeny. 2008. Historia Ocupacional y Prácticas Sociales: un análisis arqueofaunístico contextual. Sitio Piedra Horadada 2, Antofagasta de la Sierra, Catamarca, Argentina. En: De la Puna a las Sierras: Avances y Perspectivas en Zooarqueología Andina. South American Archaeology Series de British Archaeological Reports (International Series), John \& Erica Hedges, Ltd, Oxford, UK, editado por A. D. Izeta y G. L. Mengoni Goñalons. En prensa.

Urquiza, S.V., P. Cuenya y C.A. Aschero. 2009a (2007). Química del Suelo: Un Aporte a la Tafonomía en Antofagasta de la Sierra. En: (O. M. Palacios, C. Vázquez, T. Palacios y E. Cabanillas, eds.) Arqueometría latinoamericana, volumen 1: 209-214.Comisión Nacional de Energía Atómica, Centro Atómico Constituyentes, Buenos Aires. ISBN 978-987-1323-09-8. 
Von den Driesch,A. 1976. A Guide to the Measurement of Animal Bones from Archaeological Sites.Bulletin of the Peabody Museum of Archaeology and Ethnology. No.1, Harvard University.
Walkley, A y Black, C.A. 1938. An examination of the Degtajareff's method for determining soil organic matter and a proposed modification of the chromic acid titration method. Soil Science 37: 29-38. 